\title{
PERFIL BACTERIANO DE CULTURAS DE LEITE NA REGIÃO SUDOESTE DO PARANÁ
}

(Perfil bacteriano de culturas de leite na região sudoeste do Paraná)

\author{
Giovanna Mazur Karach, Marcos Vinícius Ferrari, Elaine Longhi, Marcos Agenor Liston ${ }^{1}$ \\ ${ }^{1}$ Correspondência: maliston@hotmail.com
}

\begin{abstract}
RESUMO: Para a produção do nobre alimento leite com qualidade a sanidade do rebanho, principalmente do úbere dos animais é de extrema importância. Dessa forma a mastite, inflamação da glândula mamária é a doença mais cara na produção leiteira, e o maior prejuízo gerado por ela é a diminuição do volume produzido, na maioria das vezes invisível. O diagnóstico microbiológico é considerado a prova de ouro na descoberta do perfil microbiológico da localidade ou propriedade e fundamental na elaboração de um programa de controle e prevenção dessa enfermidade. O presente estudo foi baseado na tabulação de resultados de isolamentos microbiológicos e teve por principal objetivo informar o perfil microbiológico da região. As amostras, sem histórico clínico, eram provenientes de propriedades do sudoeste do Paraná, colhidas por veterinários ou produtores e encaminhadas ao laboratório com objetivo diagnóstico. Totalizaram 138 amostras entre o período de setembro de 2013 a setembro de 2014. Nos resultados observou-se um grande percentual de amostras negativas (19\%) e contaminadas (17\%), os quais mostram a importância de uma colheita e armazenamento corretos para um resultado satisfatório. Quanto ao perfil, os gêneros mais isolados foram o Streptococcus spp. (19\%), Staphylococcus spp. (16\%) e Nocardia spp. (8\%) e as bactérias causadoras das mastites contagiosas foram mais representativas com $56 \%$, enquanto as causadoras das mastites ambientais foram $44 \%$ do total de amostras com isolamento. Essas informações devem auxiliar os profissionais em decisões estratégicas de melhoria nas propriedades leiteiras, visto que anteriormente não havia nenhum trabalho como esse na importante bacia leiteira do sudoeste do estado.
\end{abstract}

Palavras-chave: isolamento; mastite; microrganismos

\begin{abstract}
For the production of the noble food milk with quality, the health of the cattle and their udder is the most important one. In this way, the mastitis, inflammation of the mammary gland is the most expensive disease in the milk production, and the most damage caused by it is the reduction of the volume produced, mostly invisible. The diagnosis microbiological is considered the gold proof is the discovery of the microbiological profile of the local or the farms and principal in the elaboration of a control program and prevention of this disease. This study was based on the tab of the results of microbiological insulation and was aimed to inform the microbiological profile the region. The samples, without historical clinical, were from the farm of the southwest of Paraná, picked up by veterinarians or farmers and forwarded to the laboratory with an objective diagnosis. A hundred and thirty-eight samples were totaled between the period September 2013 to September 2014. The results showed a great percentage of negative samples (19\%) and contaminated (17\%), which shows the importance of a correct harvest and storage for a satisfactory result. As profile, the most isolated gender were the Streptococcus spp. (19\%), Staphylococcus spp. (16\%) and Nocardia spp. (8\%) and the bacteria that cause of mastitis - causing were the most representative with $56 \%$, while causing environmental mastitis were $44 \%$ of the total samples with isolation. These information must help the professional in strategic decision to improve the milk farms, since previously there was not any work like this in the important dairy production of the southwest of the state.
\end{abstract}

Key Words: isolation; mastitis; microorganisms 


\section{INTRODUÇÃO}

O alimento mais nobre nutricionalmente para todas as faixas etárias, o leite, necessita ser produzido com qualidade tanto como matéria-prima para produtos lácteos, quanto para a alimentação humana direta, longe de gerar qualquer risco à saúde pública como por exemplo pelo resíduo de antibiótico (Langoni et al., 2009). A remuneração aos produtores, é um incentivo na busca pela qualidade, visto que as empresas de laticínios bonificam além do valor estipulado baseando-se em indicadores de qualidade como: contagem microbiana total (CMT), porcentagem de sólidos, porcentagem de gordura e proteína e contagem de células somáticas (CCS) do leite entregue. $O$ governo também se preocupa com a qualidade através da Instrução Normativa № 62 (IN-62), de 29 de dezembro de 2011, que estabelece padrões mínimos para que o leite possa ser comercializado.

O capital empregado não é alterado significativamente quando se passa a produzir leite com qualidade em relação a produção despreocupada com esse fator. A tão desejada qualidade depende grandemente da sanidade dos animais produtores e das suas glândulas mamárias. Portanto, a mastite, inflamação de glândula mamária, é o principal fator de impacto econômico negativo sobre a atividade leiteira, acarreta prejuízos de 10 a 15\% em vários países, no Brasil sabe-se que as perdas variam de 7 a $64 \%$, mesmo favorecido por elementos climáticos, acréscimos de produtividade e baixo custo de produção o país ainda tem muito o que melhorar em relação a qualidade do leite produzido. As perdas por essa enfermidade englobam aumento no descarte dos animais, que simboliza 14\% de prejuízo, gastos com medicação e encargos veterinários que representam $8 \%$, descarte do leite dos quartos em tratamento, 8\%; alterações na composição do leite como aumento da CCS individual e do tanque, diminuição da gordura e da lactose, mudanças no perfil proteico com aumento das imunoglobulinas e da albumina e alterações nos níveis de enzimas e minerais; e a principal das perdas é o volume de leite que se produziria a mais na ausência da mastite, invisível à maioria dos produtores (Costa, 1998; Philpot e Nickerson, 2000; Simões, 2012).

A etiologia da mastite envolve diversos fatores relacionados aos animais, como sanidade, nutrição, estresse, imunidade e características individuais; ao homem, ao ambiente, e às 150 espécies de micro-organismos patogênicos e comensais que podem desencadear a doença. É classificada quanto aos sinais em clínica e subclínica. $\mathrm{Na}$ mastite clínica observa-se sinais evidentes de inflamação na glândula, alterações físicas e organolépticas no leite como grumos, alteração na coloração, de $\mathrm{pH}$, presença de sangue; e sinais sistêmicos como febre, diminuição no consumo de matéria seca e sempre a diminuição na produção leiteira. A forma clínica da enfermidade ainda é dividida de acordo com a manifestação em: superaguda, geralmente causadas por coliformes; aguda, quando há sinais sistêmicos discretos; subaguda; crônica e gangrenosa, quando diferente das outras manifestações os tetos ficam frios e sem sinais de inflamação (Simões, 2012).

Na mastite subclínica observamse apenas alterações no leite, como aumento na concentração de íons cloro e sódio, diminuição na concentração de caseína, gordura, sólidos totais e aumento na CCS conforme o nível da infecção. Representam 70 a $80 \%$ das perdas por mastite de um rebanho, pois para cada caso de mastite clínica podem haver de 15 a 40 casos subclínicos, importantes fontes de infecção na 
propriedade e responsáveis por diminuir a produção em até $45 \%$. A mastite também é classificada quanto aos agentes causadores em: 1) contagiosa, transmitida entre os animais durante a ordenha por falhas no processo asséptico, em que os agentes habitam principalmente a glândula mamária como - Staphylococcus aureus, Estreptococos esculina negativa e Corynebacterium spp., os sinais inflamatórios são moderados e é comum haverem vários casos no mesmo rebanho; 2) ambiental, por agentes como os coliformes, Estreptococos esculina positivos e enterococos normalmente presentes em fezes, solos, água e sujidades. A infeção ocorre especialmente entre as ordenhas mas também durante a ordenha e pode atingir qualquer categoria do rebanho, são clínicas e casos mais esporádicos (Martins, 2012).

Nas últimas décadas nos EUA houve a expressiva redução nos casos de mastite em 50\%, apesar de certa deficiência na aplicação dos programas de controle, aumento do rebanho e aumento da produtividade por vaca. A tendência é a redução significativa das mastites contagiosas e o aumento na importância das mastites ambientais (Philpot e Nickerson, 2000).

O programa de controle ideal para essa enfermidade é baseado na erradicação da mastite contagiosa e no controle e diminuição da ambiental, impossível ser erradicada pela presença natural dos agentes no ambiente dos animais. Esse baseia-se nas medidas de monitoramento do rebanho através de dados de CCS individual e do tanque, CMT, teste da caneca de fundo escuro, índices de casos clínicos e subclínicos, perfil microbiológico e resistência aos antibióticos, confrontados com os dados gerais do rebanho. Outras medidas são relacionadas ao conforto térmico e ambiental dos animais, higiene na ordenha, do ordenhador, que deve ser treinado para o ofício, limpeza correta dos equipamentos de ordenha e instalações, além da manutenção dessas conforme as normas internacionais, também o tratamento de todos os animais que forem secos e imediatos dos casos clínicos de mastite sob orientação veterinária. Igualmente importante 0 descarte das vacas com infecção crônica e melhoria da genética com animais menos predispostos a enfermidade, além da nutrição com aporte de todos os nutrientes necessários para a produção, com atenção especial as vitaminas $A, E$, o selênio, cobre e betacarotenos que aumentam a resistência a mastite. Existem vacinas que podem auxiliar no programa de controle para coliformes e S. aureus reduzindo a incidência e a gravidade das mastites (Müller, 2002).

Imprescindível no controle e considerado prova de ouro é o diagnóstico microbiológico das mastites, pois gera resultados rápidos e seguros na identificação dos problemas do rebanho. Quando empregado no isolamento do agente em casos clínicos direciona a terapia a ser utilizada, auxilia na decisão do descarte e no tratamento de infecções severas que não responderam a tratamentos anteriores. Já o perfil microbiológico do tanque de resfriamento fornece uma avaliação da qualidade do leite, o status de saúde do úbere do rebanho e principalmente aponta a forma que terá o programa de controle da fazenda (Brito, 2010).

O presente trabalho teve por objetivo principal revelar o perfil bacteriano das mastites bovinas frequentes na região sudoeste do Paraná a partir da tabulação de resultados de isolamentos microbianos de amostras de leite.

\section{MATERIAL E MÉTODOS}

O presente trabalho consistiu na tabulação dos resultados de culturas bacterianas a partir de 138 amostras de 
leite realizadas no período de setembro de 2013 a setembro de 2014 .

A Figura 1 é um esquema sistemático do processo realizado no laboratório explicado no texto que segue.

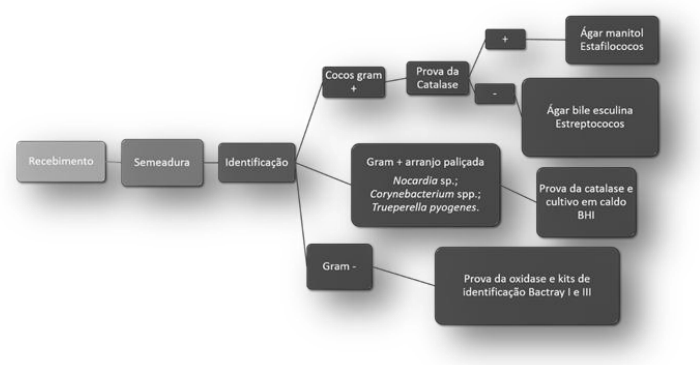

Figura 1 - llustração esquemática do processo laboratorial.

As amostras de leite congeladas ou resfriadas foram recebidas em um laboratório de diagnóstico veterinário na cidade de Francisco Beltrão, PR. Eram oriundas de propriedades da região sudoeste do Paraná, e na maioria das vezes, não eram acompanhadas de histórico clínico dos animais e foram encaminhadas por médicos veterinários ou produtores.

Ao dar entrada no laboratório, era realizada a semeadura destas amostras em placas de ágar sangue $(5 \%$ de sangue ovino) e incubadas em estufa a $37^{\circ} \mathrm{C}$, por até 72 horas em aerobiose. As colônias eram identificadas a partir da sua morfologia, aspecto, tamanho, tempo de crescimento e coradas pelo método de Gram.

Para colônias Gram positivas, em forma de cocos, era realizada a prova da catalase, quando positivas nesta prova, procedia-se semeadura em ágar manitol e em plasma de coelho para confirmação e diferenciação entre bactérias do grupo dos estafilococos. Quando as bactérias eram negativas na catalase, realiza-se semeadura em ágar bile esculina, para diferenciação de estreptococos do grupo D (segundo classificação de Lancefield).
Colônias Gram positivas com arranjo em paliçada e em forma de cocobacilos pleomórficos eram classificados como pertencentes ao grupo corineformes, entre os quais estão Nocardia spp, Corynebacterium spp, Trueperella pyogenes (Actinomyces pyogenes). Para diferenciação entre eles era realizada prova da catalase, e cultivo em $\mathrm{BHI}$ caldo.

Bactérias Gram negativas procedia-se a prova da oxidase e posteriormente era utilizado os kits de identificação para enterobactérias Bactray I e III (Laborclin $\AA$ ).

\section{RESULTADOS E DISCUSSÃO}

Na Figura 2 estão expostos em um gráfico os resultados do cultivo celular das 138 amostras recebidas no laboratório.

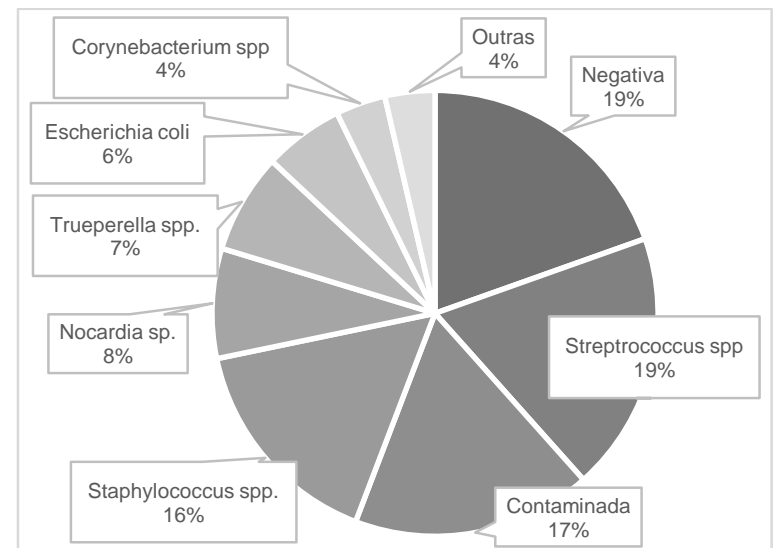

Figura 2 - Gráfico demonstrando o resultado de 138 culturas de leite realizados entre setembro de 2013 a setembro de 2014.

A maior porcentagem das amostras (19\%) foi negativa, ou seja, sem crescimento de nenhuma unidade formadora de colônia. No trabalho de Brito et al. (1999) a porcentagem de amostras negativas foi de 39 num total de 6.598 amostras no estado de Minas Gerais. Langoni et al. (2009) afirma que mais de $50 \%$ das culturas de mastites clínicas e subclínicas podem ser negativas e recomenda para essas 
amostras a repetição do exame e/ou a utilização de métodos especiais de cultura. Amostras negativas podem ser resultado do possível desaparecimento espontâneo do microrganismo, destruição desse pelo processo inflamatório na glândula mamária ou ainda por resíduo de antibiótico; pela eliminação intermitente do agente em casos de infecção crônica ou a presença do agente reduzida no leite, o que dificulta o crescimento no laboratório. Outros fatores que podem levar a resultados negativos são as mastites causadas por agentes como: Mycoplasma spp, Leptospira spp, Campylobacter spp, fungos e vírus que exigem condições diferenciadas para a multiplicação e identificação. Também pelo fato de existirem etiologias não infecciosas e sim por fatores tóxicos, metabólicos, alérgicos ou traumáticos (Costa, 1998).

As amostras contaminadas também obtiveram destaque nos resultados com $17 \%$ do total. São classificadas como contaminadas as amostras que quando cultivadas observa-se a presença de várias unidades formadoras de colônia com diferentes tamanhos, formas e cores entre si. No trabalho de Pardo et al. (1999) realizado na região de Arapongas - PR no total de 232 amostras, 8,7\% cresceram com contaminantes, sabendo que as amostras foram colhidas com devido o cuidado pelos autores, e no presente trabalho foram colhidas por veterinários de campo ou por produtores. A colheita e o armazenamento realizados de uma forma correta são fundamentais para um resultado confiável, essa forma deve ser cada vez mais praticada pelos médicos veterinários e repassada a orientação aos produtores. Para se obter uma amostra asséptica é necessário higienizar os tetos a serem colhidos com algodão embebido em álcool 70\% iniciando pelos tetos distais. Assim que secarem descartar os três primeiros jatos de leite por terem a contaminação presente no canal do teto, colher em tubo estéril, um para cada teto afetado dos proximais para os distais sem encostar a parte interna do tubo nos tetos ou em outro local e fechar os tubos adequadamente (Philpot e Nickerson, 2000).

As amostras devem ser acondicionadas em recipientes com gelo (temperatura 4 a $5^{\circ} \mathrm{C}$ ) imediatamente após a colheita, e mantidas nestas condições por no máximo 24 horas até serem entregues no laboratório. Caso contrário não poderão ser utilizadas para diagnóstico bacteriológico. A refrigeração é importante para impedir que a população de um contaminante sobreponha a do patógeno de interesse. Uma alternativa nos casos em que a amostra não chegará no laboratório em 24 horas é a congelação por períodos curtos de até quatro semanas antes do exame. Períodos maiores poderão afetar o isolamento de algumas bactérias (Brito, 2010).

O gênero bacteriano mais isolado neste trabalho foi o Streptococcus spp. com 26 isolamentos (19\%) do total de 138, seguido pelo gênero Staphylococcus spp. representando $16 \%$ como ilustrado na figura 1. Laffranchi et al. (2001) encontrou mais de $76 \%$ do gênero estafilococos e apenas $8,1 \%$ de estreptococos na região norte do Paraná e sudoeste de São Paulo, como a maioria dos trabalhos, observou resultados maiores para isolamento de estafilococos. Em Barbalho e Mota (2005) realizado no estado de Pernambuco, os isolamentos de estreptococos representaram $4,65 \%$ de um total de 129 amostras e de estafilococos mais de $38 \%$; também em Pernambuco Freitas et al. (2005) obteve resultados de $49,6 \%$ de estafilococos, $34,8 \%$ de corinebactérias e apenas 3,8\% de estreptococos.

$\mathrm{Na}$ região metropolitana de Curitiba, Andrade et al. (2009) encontrou 
$52,2 \%$ de estafilococos em 966 amostras e $26 \%$ para estreptococos. Essa maior frequência nos isolamentos de bactérias do gênero Streptococcus spp. contrária os trabalhos citados e pode estar relacionada ao fato de não haverem estudos no sudoeste do Paraná como esse.

O resultado dos isolamentos também mostra outros gêneros importantes: Nocardia spp. com $8 \%$ dos isolamentos, Trueperella spp. com $7 \%$, Escherichia coli com 6\%. O gênero Corynebacterium spp. representou $4 \%$ do total de amostras isoladas, número inferior ao encontrado em todos os trabalhos já citados e nos resultados de Saab et al (2014) com isolamento de $14,2 \%$ de um total de 155 amostras de Nova Tebas, região central do estado do Paraná. O gênero Corynebacterium é composto por 112 espécies porém a mais importante na mastite é a $C$. bovis. Esse micro-organismo é comensal no úbere e segundo uma linha de autores protege da infecção por S. aureus e outras bactérias mais patogênicas. Em alguns casos torna-se o agente primário de mastites clínicas e subclínicas, em que o quadro geral do animal é bom mas o leite apresenta aspecto purulento (Gomes, 2013).

Outras representaram $4 \% \quad$ e englobam as bactérias Klebsiella spp, Proteus mirabilis e Serratia spp. que normalmente são isoladas em pequenas quantidades nos trabalhos.

$\mathrm{Na}$ Tabela 1 estão expostos 0 número e porcentagem das bactérias isoladas divididas em dois grupos, agentes contagiosos e agentes ambientais excluindo os resultados negativos e contaminados.

Tabela 1 - Agentes contagiosos e ambientais isolados em 85 amostras de leite da região sudoeste do Paraná no período de setembro de 2013 a setembro de 2014.

\begin{tabular}{lcc}
\hline \multicolumn{1}{c}{ Agentes } & FA & FR \\
\hline \multicolumn{1}{c}{ Contagiosos } & $\mathbf{4 8}$ & $\mathbf{5 6 \%}$ \\
Streptococcus spp. esculina negativo & 21 & $25 \%$ \\
Staphylococcus aureus & 17 & $20 \%$ \\
Corynebacterium spp. & 5 & $6 \%$ \\
Staphylococcus spp. coagulase negativo & 5 & $6 \%$ \\
\hline Ambientais & $\mathbf{3 7}$ & $\mathbf{4 4 \%}$ \\
\hline Nocardia spp. & 11 & $13 \%$ \\
Trueperella pyogenes & 10 & $12 \%$ \\
Escherichia coli & 8 & $9 \%$ \\
Streptococcus spp. esculina positivo & 5 & $6 \%$ \\
Klebsiella spp & 1 & $1 \%$ \\
Serratia spp & 1 & $1 \%$ \\
Proteus mirabilis & 1 & $1 \%$ \\
\hline \multicolumn{1}{c}{$\quad$ Total } & $\mathbf{8 5}$ & $\mathbf{1 0 0} \%$ \\
\hline
\end{tabular}

FA - frequência absoluta

FR - frequência relativa

É possível observar a maior frequência dos agentes contagiosos (56\%) sobre os ambientais (44\%). Em um estudo realizado em Altônia-PR os agentes contagiosos representaram $81,48 \%$ dos isolamentos, explicado pelos autores como decorrência de um manejo inadequado durante a ordenha (Oliveira et al., 2013). Dentre os agentes classificados como contagiosos segundo Costa (1998) o que mais se destacou foi - Streptococcus spp. esculina negativa com $25 \%$ das 85 amostras isoladas, em que o mais importante é o $S$. agalactiae. Na glândula mamária cronicamente leva a formação de tecido fibroso, e na fase aguda ocorre tumefação, possível febre e reduz consideravelmente a produção leiteira do teto acometido. Apenas um animal infectado é capaz de elevar a CCS do tanque e essa bactéria possui alta eliminação, rapidamente disseminada no rebanho.

O gênero estafilococos pode ser dividido em dois grupos quanto a prova da catalase, dos chamados coagulase positivos (ECP), classe mais patogênica, o $S$. aureus é o mais importante relacionado a mastite, e nesse caso foi mais isolado em relação aos coagulase negativos. Sua infecção é facilitada por feridas e a fonte são tetos acometidos com a presença do agente (Hirsh, 2003). 
A transmissão ocorre pela ordenhadeira, mão do ordenhador e objetos utilizados para limpeza dos tetos. Geralmente as infecções se apresentam subclínicas com episódios esporádicos clínicos, em que há edema e coágulos no teste da caneca de fundo escuro, algumas infecções podem tornar-se gangrenosas. O tratamento é considerado difícil, pois a bactéria forma abcessos e envelopamento por tecido fibroso diminuindo o contato do antibiótico com a bactéria (Philpot e Nickerson, 2000).

A diferença quanto aos outros Staphylococcus spp. pertencentes ao grupo dos coagulase negativo (ECN) é esses serem menos agressivos, provocam mastites com sinais clínicos raros e cura espontânea em grande parte dos quadros. No presente trabalho representou apenas $6 \%$ nos resultados, enquanto em Barbalho e Mota (2005) foi de 18\%, e em Domingues (2005) representou 36 dos 53 isolamentos de leite ovino em Jaboticabal, São Paulo.

Os agentes ambientais foram isolados em 37 das 85 amostras (44\%). Esses agentes penetram no canal do teto mais comumente no período seco ou nos animais em lactação entre as ordenhas. As infecções têm um curso de trinta dias em média, $18 \%$ tornam-se cronicas e podem durar até 100 dias (Philpot e Nickerson, 2000).

Nesse grupo de agentes estão inclusos os estreptococos esculina positiva, coliformes e os enterococos. A Nocardia sp. representou $13 \%$ do total de isolamentos no trabalho, são bactérias gram positivas presentes normalmente nos solos e água, que quando contaminada gera a infecção nos animais, apresenta-se de forma aguda com hipertermia, pode tornar-se um processo crônico e gerar também pneumonia secundária. A mastite é piogranunomatosa portanto o tratamento é considerado difícil (Martins, 2012). Em Ziech et. al. (2011) o gênero Nocardia sp. representou $5,76 \%$ de 1997 amostras nos três estados do sul do país, mas a frequência nas amostras provenientes do Paraná foi de $10 \%$, bem próxima a encontrada no presente trabalho.

A Trueperella pyogenes era chamada de Arcanobacterium pyogenes até a nova classificação em Yassin et. al. (2011). Conhecida por causar endocardite, abcessos hepáticos, endometrite, aborto e a chamada "mastite de verão", chamada dessa forma por ser transmitida no rebanho por insetos e ser mais comum nos meses quentes do ano e no período seco dos animais. A forma da bactéria penetrar nos tetos é por lesões, a doença é severa com possíveis fístulas que drenam pus, nódulos e abcessos e de difícil eliminação com antibióticos (Gomes, 2013). Nesse estudo foi isolada em dez das 85 amostras (12\%), em outro estudo realizado em uma propriedade de São Paulo a frequência foi de $17 \%$ em 216 animais e foi considerado um surto ocorrido nos meses de janeiro e fevereiro de 2010 (Motta et al., 2011). Já em Pardo et. al. (1999) representou 5,08\% de 168 amostras em Arapongas-PR.

A Escherichia coli foi isolada em 8 das 85 amostras (9\%) número inferior ao encontrado em Andrade e Masson (2009) de $13,6 \%$ e superior a $2,35 \%$, dois isolamentos em 85 amostras de Müller et al. (1978). A mastite causada pela E. coli é clínica, aguda ou hiperaguda e alguns quadros são subclínicos e ocorre geralmente nas primeiras semanas pós parto pelo estresse imunológico dessa fase, os neutrófilos demoram mais a chegar no quarto afetado. Fatores de virulência desse agente como endotoxinas, exotoxinas, replicação em restrição de ferro e multirresistência a antibióticos fazem com que o tratamento seja improvável durante a mesma lactação e haja comprometimento sistêmico e até óbito (Ribeiro et al., 2006).

Classificados como agentes ambientais os estreptococos esculina 
positivo obtiveram uma frequência de $6 \%$ conforme a Tabela 1 , diferente do que encontra-se na literatura em que são descritos como os principais agentes das mastites ambientais representando até $85 \%$ desse tipo de mastite, por serem amplamente disseminados no ambiente dos animais, principalmente nas camas de sistemas de confinamento, mas também em sistemas de pastejo durante todo o ano. A enfermidade causada por esses agentes é na maior parte subclínica, até 95\%; e em alguns casos clínica e crônica, atingindo mais de uma lactação do mesmo animal. Ocorre geralmente no período próximo ao parto e sua importância é crescente, pois o número de infecções aumenta no mundo com a atual tendência da redução das mastites contagiosas (Loures, 2011).

\section{CONCLUSÃO}

O presente estudo revelou o perfil bacteriano das amostras de leite colhidas de tetos acometidos por mastite na região sudoeste do Paraná. Uma porcentagem bastante significativa para amostras negativas e contaminadas foi observada, e através desses dados concluímos a importância de uma colheita e armazenamento das amostras corretos. O gênero bacteriano mais isolado foi o Streptococos seguido pelo Stafilococos, diferente de resultados encontrados em outros trabalhos, e as bactérias consideradas contagiosas foram mais isoladas que as ambientais, o que corresponde ao cenário nacional. O conhecimento desse perfil microbiológico regional deve auxiliar os profissionais no programa de controle das mastites através de medidas mais específicas e nas decisões do rebanho. Também reafirma a relevância do exame microbiológico do leite na prevenção, controle e tratamento dessa enfermidade.

\section{REFERÊNCIAS}

ANDRADE, U., W. H.; MASSON M. L. "Isolamento microbiologico, contagem de células somáticas e contagem bacteriana total em amostras de leite." Ars Veterinaria 25.3 (2010): 129-135. Disponível em: $<$ http://arsveterinaria.org.br/index.php/ars/article/ view/307>

BARBALHO, C.F.T.; MOTA, A.R. Isolamento de agentes bacterianos envolvidos em mastite subclinica bovina no Estado de Pernambuco. Revista Brasileira de Saúde e Produção Animal, v. 2, n. 2, 2005. Disponível em: <http://revistas.ufba.br/index.php/rbspa/article/vi ewArticle/604>

BRITO, M.A.V.P. Diagnóstico microbiológico da mastite bovina. Informativo Técnico Embrapa Gado de Leite. 2010.

BRITO, M. A. V., BRITO, J. R., RIBEIRO, M. T., et al. (1999). Padrão de infecção intramamária em rebanhos leiteiros: exame de todos os quartos mamários das vacas em lactação. Arq. Bras. Med. Vet. Zootec, 51(2), 129-35. Disponível em: <http://bases.bireme.br/cgibin/wxislind.exe/iah/o nline/?IsisScript=iah/iah .xis \&src=google\&base $=\mathrm{L}$ ILACS\&lang=p\&nextAction=Ink\&exprSearch $=26$ 0961\&indexSearch $=I D>$

COSTA, E. O. "Importância da mastite na produção leiteira do país." Revista de Educação Continuada em Medicina Veterinária e Zootecnia1.1 (1998). Disponível em: $<$ http://revistas.bvs-

vet.org.br/recmvz/article/view/3381>

DOMINGUES, P. F.; LUCHEIS, S. B.; SERRÃO, L. S., et al. (2006). Etiologia e sensibilidade bacteriana da mastite subclínica em ovelhas da raça santa inês. Ars Veterinaria, 22(2), 146-152. Disponível

em: http://www.arsveterinaria.org.br/index.php/ars/art icle/view/94

FREITAS, M. F. L.; PINHEIRO, J. W.J.; STAMFORD, T. L. M., et al. (2005). Perfil de sensibilidade antimicrobiana in vitro de Staphylococcus coagulase positivos isolados de leite de vacas com mastite no agreste do estado de Pernambuco. Biológico, São Paulo, 72(2), 171-177. Disponível em: <http://200.144.6.109/docs/arq/V72_2/freitas.PD $\mathrm{F}>$

GOMES, M. J. P. Gênero Streptococcus spp. 2013. FAVET-UFRGS Disponível em: http://www.ufrgs.br/labacvet/files/G\%C3\%AAner ०\%20Streptococcus\%204-2013-1.pdf 
GOMES, M. J. P. Gênero Staphylococcus spp. 2013. FAVET-UFRGS Disponível em: http://www.ufrgs.br/labacvet/files/G\%C3\%AAner ०\%20Staphylococcus\%20spp\%204-2013-1.pdf

GOMES, M. J. P. Gêneros Corynebacterium, Rhodococcus e Trueperella spp 2013. FAVETUFRGS Disponível em: <http://www.ufrgs.br/labacvet/files/G\%C3\%AAne ro\%20Coryne-Rhodo-Trueperella\%204-20131.pdf>

LAFFRANCHI, A.; MULLER, E. E.; FREITAS, J. C.; et al. Etiologia das infecções intramamárias em vacas primíparas ao longo dos primeiros quatro meses de lactação. Ciência Rural, v.31, n.6, p.1027-1032, 2001

LANGONI, H.; LAURINO, F.; FACCIOLI, P.Y. et al. Cultivo Microbiológico e a Sensibilidade no isolamento de patógenos nas mastites bovinas. Vet. E Zootec., p. 708-715, v.16, n 4, dez, 2009.

LOURES, R. A. Diversidade genética, fatores de virulência e resistência a antimicrobianos em Streptococcus uberis isolados em mastite bovina. Lavras, 2011. Dissertação (Mestrado do Programa de Pós-Graduação em Ciências Veterinárias). Universidade Federal de Lavras.

MARTINS, J. D. Estudo da etiologia as principais bactérias isoladas de mastite bovina em rebanhos leiteiros de propriedades rurais de goiás. 2012. p.102. Dissertação (Mestrado em Ciência Animal - Escola de Veterinária e Zootecnia da Universidade Federal de Goiás).

MOTTA, R.G.; RIBEIRO, M.G.; PERROTTI, I.B.M. et al. Surto de mastite bovina causada por Arcanobacterium pyogenes. Arq. Bras. Med. Vet. Zootec., v.63, n.3, p.736-740, 2011.

MÜLLER, E. E. Qualidade do leite, células somáticas e prevenção da mastite. Simpósio sobre Sustentabilidade da Pecuária Leiteira na Região Sul do Brasil, v. 2, p. 206-217, 2002. Disponível em: http://people.ufpr.br/ freitasjaf/artigos/qualidadel eitem.pdf

MÜLLER, E. E.; SOUZA JR., J.M.; MARQUES, F. A. C. et al. Estudo da Prevalência de Mastite Bovina. SEMINA; vol.1 p. 47-48. Abril/junho 1978.

OLIVEIRA, J. L. P.; KOZERSKI, N. D.; SILVA, D. $R$. et al. Fatores de risco para mastite e qualidade do leite no município de Altônia -PR. Arq. Ciênc. Vet. Zool. UNIPAR, Umuarama, v. 16, n. 1, p. 6172, jan./jun. 2013.

PARDO, R. B.; STURION, D. J.; BASILE, J. R. et al. Levantamento dos agentes etiológicos da mastite bovina na região de Arapongas (PR).
UNOPAR Cient., Ciênc. Biol. Saúde, Londrina, v. 1, n. 1, p. 25-30, out. 1999.

PHILPOT, W. N., NICKERSON, S. C. Vencendo a luta contra a mastite. Westfalia Landtechnik do Brasil, 2000.

RIBEIRO, M. G., COSTA, E. O., LEITE, D. S., et al. (2006). Fatores de virulência em linhagens de Escherichia coli isoladas de mastite bovina. Arq. bras. med. vet. zootec,58(5), 724-731. 2006.

SAAB A.B.; ZAMPROGNA, T. O.; LUCAS T. M. Prevalência e etiologia da mastite bovina na região de Nova Tebas, Paraná. Semina: Ciências Agrárias, Londrina, v. 35, n. 2, p. 835-844, mar./abr. 2014

SIMÕES, T.V.M.D. Mastite bovina: considerações e impactos econômicos Aracaju: Embrapa Tabuleiros Costeiros, 2012. 25 p. (Documentos / Embrapa Tabuleiros Costeiros, ISSN 1678-1953; 170). Disponível em $<$ http://www.cpatc.embrapa.br/publicacoes_2012 / doc_170.pdf>

ZIECH, R., KOWALSKI, A. P., FARIAS, L. D. A., et al. DIAGNÓSTICO DE Nocardia spp. EM AMOSTRAS DE LEITE BOVINO MASTÍTICO NOS ESTADOS DO SUL DO BRASIL. 2011. Disponível em $<$ http://www.sovergs.com.br/site/38conbravet/res umos/558.pdf> 